Y/EN-8270

May 26, 2009

The use of Tl-208 gamma rays for safeguards, nondestructive-assay (NDA) measurements

\author{
R. B. Oberer \\ L. G. Chiang \\ M. J. Norris \\ C. A. Gunn \\ B. C. Adaline
}

Prepared by

Babcock \& Wilcox Technical Services Y-12, LLC

Management \& Operating Contractor

for the

Y-12 National Security Complex

under Contract No. DE-AC05-00OR22800

with the

U.S. Department of Energy

National Nuclear Security Administration 
Y/EN-8270

May 26, 2009

\section{Disclaimer}

This report was prepared as an account of work sponsored by an agency of the United States Government. Neither the United States Government nor any agency thereof, nor any of their employees, makes any warranty, express or implied, or assumes any legal liability or responsibility for the accuracy, completeness, or usefulness of any information, apparatus, product, or process disclosed, or represents that its use would not infringe privately owned rights. Reference herein to any specific commercial product, process, or service by trade name, trademark, manufacturer, or otherwise, does not necessarily constitute or imply its endorsement, recommendation, or favoring by the United States Government or any agency thereof. The views and opinions of authors expressed herein do not necessarily state or reflect those of the United States Government or any agency thereof. 
Y/EN-8270

May 26, 2009

\title{
The use of Tl-208 gamma rays for safeguards, nondestructive-assay (NDA) measurements
}

\author{
R. B. Oberer \\ L. G. Chiang \\ M. J. Norris \\ C. A. Gunn \\ B. C. Adaline \\ Y-12 National Security Complex \\ Oak Ridge, Tennessee
}

\begin{abstract}
This paper examines two cases where gamma rays from Tl-208, including the $2614 \mathrm{keV}$ gamma ray, were used to detect anomalies in waste material. In addition to the characterization of waste for waste acceptance, and compliance with environmental and transportation laws, there is a safeguards element as well. The more sophisticated method of NDA at Y-12 includes a means to detect shielded special nuclear material (SNM). Excess count rates in the $2614 \mathrm{keV}$ gamma ray from Tl-208 are an indication of potential shielded HEU in waste as well as other containers. The $2614 \mathrm{keV}$ gamma ray is easy to monitor routinely. When a large $2614 \mathrm{keV}$ peak is detected, further investigation can be conducted from the gamma spectrum. This paper describes this further investigation in two cases. In one case self-shielded HEU was detected. In the other case the Tl-208 gamma rays came from a piece of Th-232 metal.
\end{abstract}

\section{Introduction}

Virtually all weapons grade HEU contains small quantities of U-232 introduced from the production of plutonium. ${ }^{1}$ Natural uranium was irradiated in reactors at Hanford and at Savannah River to produce plutonium before the uranium was enriched. There is therefore a small quantity of U-232, somewhat less than one part per billion, in weapons grade HEU. Because of the short 72 year half-life, U-232 has a very high specific activity. Therefore, even though it is present in low concentrations, it functions as an effective tracer isotope in HEU.

The most prominent gamma ray from $\mathrm{U}-235$ is the $186 \mathrm{keV}$ gamma ray. All of the gamma rays from U-235 with any appreciable emission rate are $205 \mathrm{keV}$ or lower. Because of the low energy, these gamma rays are easily shielded. The mean free path of the 186kev gamma ray in lead is less than a millimeter and about a third of a millimeter in uranium. The small quantity of U-232 present in HEU emits substantially higher energy gamma rays. The $2614 \mathrm{keV}$ gamma ray from Tl-208 in the decay chain of U-232

\footnotetext{
${ }^{1}$ A.J. Peurrung, "Predicting ${ }^{232}$ U Content in Uranium," PNNL-12075, December 1998.
} 
Y/EN-8270

May 26, 2009

has a mean free path of $20 \mathrm{~cm}$ in lead and $12 \mathrm{~cm}$ in uranium. This gamma ray is therefore much more difficult to shield. ${ }^{2}$

The interpretation of the $2614 \mathrm{keV}$ gamma ray is complicated by the fact that it comes from both U-232 and Th-232. The isotope Tl-208 is produced by the decay of both U232 and Th-232 as shown in Figure 1. Both decay chains join at the Th-228 isotope. Th-232 decays through Ac-228 to Th-228, producing several characteristic gamma rays. It is the decay of Ac-228 and associated gamma rays that distinguish Th-232 from U-232. When a large $2614 \mathrm{keV}$ peak is detected, further investigation can be conducted from the gamma spectrum. This paper describes this further investigation in two cases. In one case self-shielded HEU was detected. In the other case the Tl-208 gamma rays came from a piece of Th-232 metal.

\section{Analysis}

This section describes the analysis used by ISOTOPIC software to produce the differential attenuation plots shown in Figures 2a through 3b. These plots show the percent difference in activity calculated for various gamma ray energies from an isotope, compared to a reference gamma ray. The reference gamma rays for each uranium, thorium, and thalium isotope are shown as shaded in Table 2. The activities are calculated as follows. The activity of an isotope calculated from the $\mathrm{i}^{\text {th }}$ gamma ray is

$$
A_{i}=\frac{R_{i}}{Y_{i} \varepsilon_{i}}
$$

where $R_{i}$ is the count rate of the $\mathrm{i}^{\text {th }}$ gamma ray at energy $E_{i}, Y_{i}$ is the branching ratio of the $\mathrm{i}^{\text {th }}$ gamma ray, and $\varepsilon_{i}$ is the total detection efficiency for this gamma ray. A list of the gamma ray energies for each of the isotopes analyzed in these two cases is shown in Table 2.

The detection efficiency includes the intrinsic efficiency of the detector, as well as geometry, and attenuation. For implementation of the differential attenuation method, each component of the detection efficiency is separated into the factors

$$
\varepsilon_{i}=G \varepsilon_{I i}\left(C F_{c}\right)\left(C F_{m}\right)
$$

where $G$ is a geometry factor, $\varepsilon_{I i}$ is the intrinsic detection efficiency, $\left(C F_{c}\right)$ is a correction factor for attenuation caused by the container, and $\left(C F_{m}\right)$ is a correction factor for attenuation caused by the matrix and uranium. All of the factors are energy dependent except the geometry factor. The geometry factor and its uncertainty are shown in Table 1.

\footnotetext{
${ }^{2}$ R.B. Oberer, L.G. Chiang, M.J. Norris, C.A. Gunn, D.R. Eblen, "Determination of Uranium Concentration and Attenuation Correction in Dense Highly Enriched Uranium (HEU) Material by the Comparison of Gamma Rays from Tl-208," 49th Annual Meeting of the Institute of Nuclear Materials Management (INMM) 13-17 July 2008 Nashville, Tennessee.
} 
The detection efficiency may also involve a collimator correction factor when the item being measured is close to the detector compared to the size of the item. In this analysis the distance is great enough to ignore the collimator correction factor.

The correction factor ${ }^{3}$ for the container is typically known. It is calculated as

$$
C F_{c}\left(\mu(E)_{c} \rho_{c} x_{c}\right)=T_{C}
$$

where the transmission can be measured or calculated as $T_{c}=e^{(-\mu(E) \rho x)_{c}}$ from the massattenuation coefficient $\mu(E)_{c}$, the density $\rho_{c}$, and thickness $x_{c}$ of the container.

The matrix correction factor depends on the composition of the matrix. The term matrix means the isotope of interest and other material that it is mixed with. Thorium and uranium isotopes can contribute significantly to the attenuation. The matrix attenuation correction is calculated as

$$
C F_{m}\left(\mu(E)_{m} \rho_{m} x_{m}\right)=\frac{1-T_{m}}{\mu(E)_{m} \rho_{m} x_{m}}
$$

where the transmission is $T_{m}=e^{-(\mu(E) \rho x)_{m}}$.

The ISOTOPIC software allows the container thickness $x_{c}$, matrix density $\rho_{m}$, and fraction of uranium used to calculate $\mu(E)_{m}$ to be adjusted. These parameters are adjusted with a slide bar as shown in Figures 2a to 3b. Ideally with the correct adjustment, all of the gamma rays from an isotope produce the same calculated activity from equation (1) and a zero percent difference in the graph.

\footnotetext{
${ }^{3}$ Note that the correction factors are in the denominator of Equation (1) a part of the efficiency. They are therefore inverted from the form often seen.
} 
Y/EN-8270

May 26, 2009

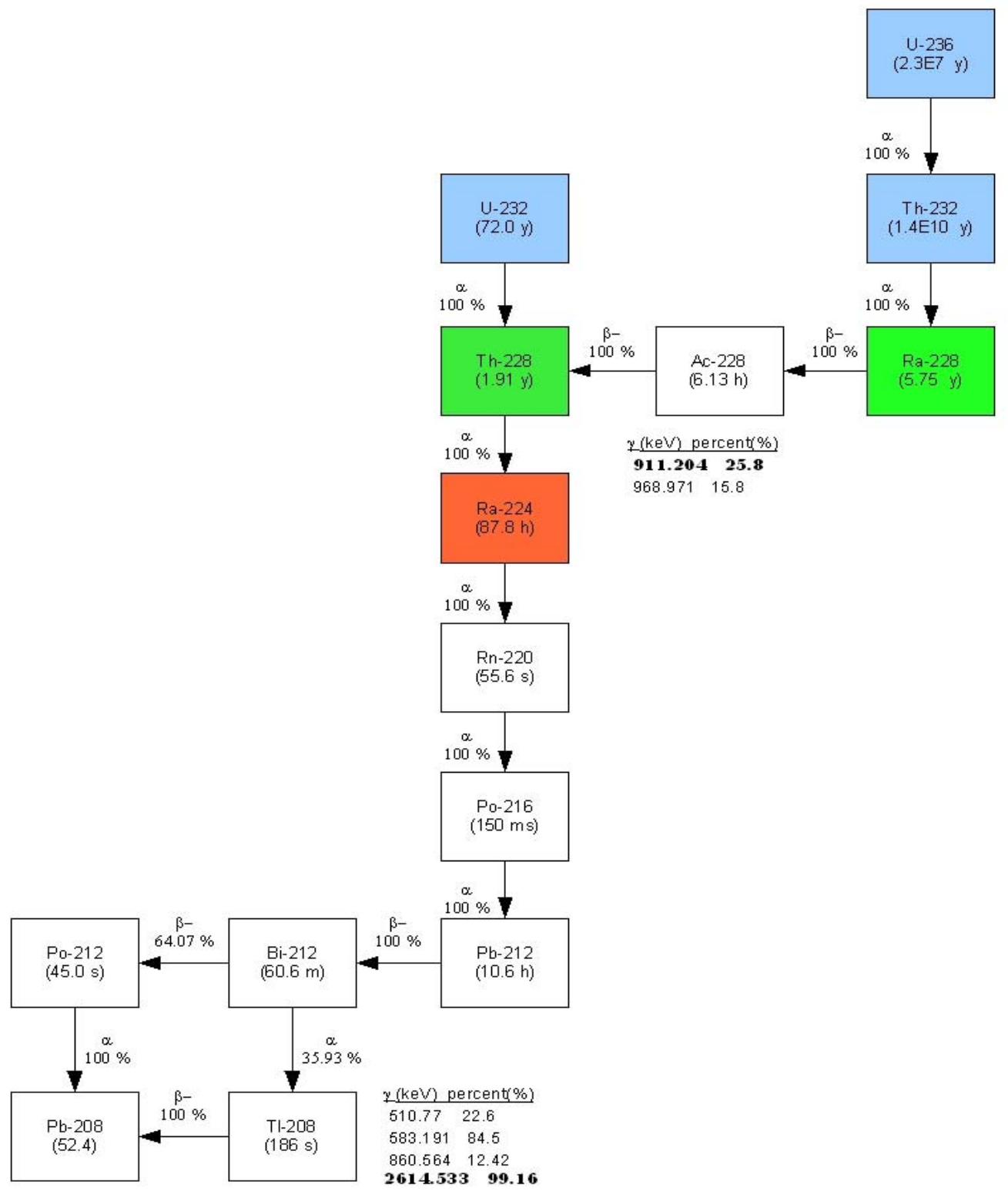

Figure 1. The decay chain of U-232 and Th-232. U-236 is also shown. It is typically also present when U232 is present. U-236 never goes into secular equilibrium because of the long half life of Th-232.

\section{Investigation}

In the first case, a 55 gallon drum of combustibles had a count rate in the $2614 \mathrm{keV}$ peak that was 3.8cps which was 25 times higher than background, but had only $0.7 \mathrm{~g}$ of U-235 based on the analysis of the $186 \mathrm{keV}$ gamma ray peak. A 5 in by 3 in by $0.1 \mathrm{in}, 297 \mathrm{~g}$ piece of thorium metal was later found in the drum. In the second case, a hospital can purportedly containing contaminated combustibles had a count rate in the $2614 \mathrm{keV}$ peak 
Y/EN-8270

May 26, 2009

that was $2.6 \mathrm{cps}$, which was 17 times background. It turned out that the can contained $2.1 \mathrm{~kg}$ of small HEU metal pieces in the bottom of the can.

Table 1. Various parameters and data for the 55 gallon drum and the hospital can.

\begin{tabular}{|l|r|r|}
\hline & \multicolumn{1}{|l|}{ Drum } & Hospital can \\
\hline Gross Weight (kg) & 39.1 & 2.843 \\
\hline Tare Weight (kg) & 27.5 & 1.184 \\
\hline Net Weight (kg) & 11.6 & 1.659 \\
\hline Wall thickness (in) & 0.064 & 0.059 \\
\hline Height (in) & 30 & 7.6 \\
\hline Diameter (in) & 23 & 6.5 \\
\hline Geometry Factor & 10.38 & 1.95 \\
\hline $\begin{array}{l}\text { Geo Fact } \\
\text { Uncertainty (\%) }\end{array}$ & 26.5 & 15.5 \\
\hline $\begin{array}{l}\text { 2614keV peak } \\
\text { (cps) }\end{array}$ & 3.8 & 2.6 \\
\hline 911keV peak (cps) & 5.1 & 0.1 \\
\hline
\end{tabular}

Table 2. Libraries used in analysis showing isotope and gamma ray energies. The shaded energies are the reference gamma ray.

\begin{tabular}{|l|r|}
\hline \multicolumn{2}{|l|}{55 gallon drum } \\
\hline Isotope & $\begin{array}{c}\text { Energy } \\
(\mathrm{keV})\end{array}$ \\
\hline U-235 & 143.76 \\
\hline & 163.35 \\
\hline & 185.72 \\
\hline & 205.31 \\
\hline Th-232 & \\
\hline Pb-212 & 238.63 \\
\hline Ac-228 & 270.30 \\
\hline Ac-228 & 338.40 \\
\hline Tl-208 & 583.25 \\
\hline Bi-212 & 727.17 \\
\hline Ac-228 & 911.07 \\
\hline Ac-228 & 968.90 \\
\hline Ac-228 & 1587.9 \\
\hline & \\
\hline
\end{tabular}

\begin{tabular}{|l|c|}
\hline \multicolumn{2}{|l|}{ Hospital can } \\
\hline Isotope & $\begin{array}{c}\text { Energy } \\
(\mathrm{keV})\end{array}$ \\
\hline U-235 & 105.00 \\
\hline & 109.14 \\
\hline & 143.76 \\
\hline & 163.35 \\
\hline & 185.72 \\
\hline & 202.12 \\
\hline & 205.31 \\
\hline TL-208 & 277.36 \\
\hline & 510.72 \\
\hline & 583.14 \\
\hline & 763.30 \\
\hline & 860.47 \\
\hline & 2614.47 \\
\hline
\end{tabular}

Thorium was suspected in the drum because the count rate in the $911 \mathrm{keV}$ gamma ray peak was 5.1cps which was greater than the count rate in the $2614 \mathrm{keV}$ peak. Because of this high count rate in the $911 \mathrm{keV}$ peak, the spectrum was analyzed with a thorium library. The relevant gamma rays are shown in Table 2. From the initial analysis shown in Figure 2a, the activities from various daughters of Th-232 are consistent with secular equilibrium, but under-corrected for attenuation. If U-232 contributed to this activity, the Ac-228 gamma rays would appear underrepresented. The few gamma rays from the U235 appear to have an unbiased correction for attenuation. Therefore, the uranium would seem to be homogenously distributed in the combustible, but the thorium is either 
shielded or concentrated in a lump. Assuming a lump of thorium metal, ${ }^{4}$ the uranium fraction is set to 1.0 in Figure 2b. We are substituting the attenuation of uranium as a first approximation to thorium because it is readily available in the software. The density of the matrix is also increased until the thorium gamma rays lie as close to the zero line as possible. Keep in mind that this density $0.22 \mathrm{~g} / \mathrm{cc}$ is $58.42 \mathrm{~cm}$ thick in the 55 gallon drum model. The density thickness of the thorium is therefore $12.85 \mathrm{~g} / \mathrm{cm}^{2}$. Again, assuming thorium metal with a density of $11.72 \mathrm{~g} / \mathrm{cc}$, a thickness of thorium metal of $1.1 \mathrm{~cm}$ is the same density thickness. With this density thickness, a total of $144 \mathrm{~g}$ of Th-232 is calculated from the gamma-ray emission. A $5 \mathrm{in}$ by 3 in by $0.1 \mathrm{in}, 297 \mathrm{~g}$ piece of thorium metal was later found in the drum. From Figure $2 b$, the U-235 is clearly overcorrected by the same parameters that correctly attenuate the thorium gamma rays. Therefore the uranium is not attenuated by the lump of thorium. The original $0.7 \mathrm{~g} \mathrm{U}-235$ is the most likely value. The gamma rays from the U-235 should not be corrected for the thorium attenuation

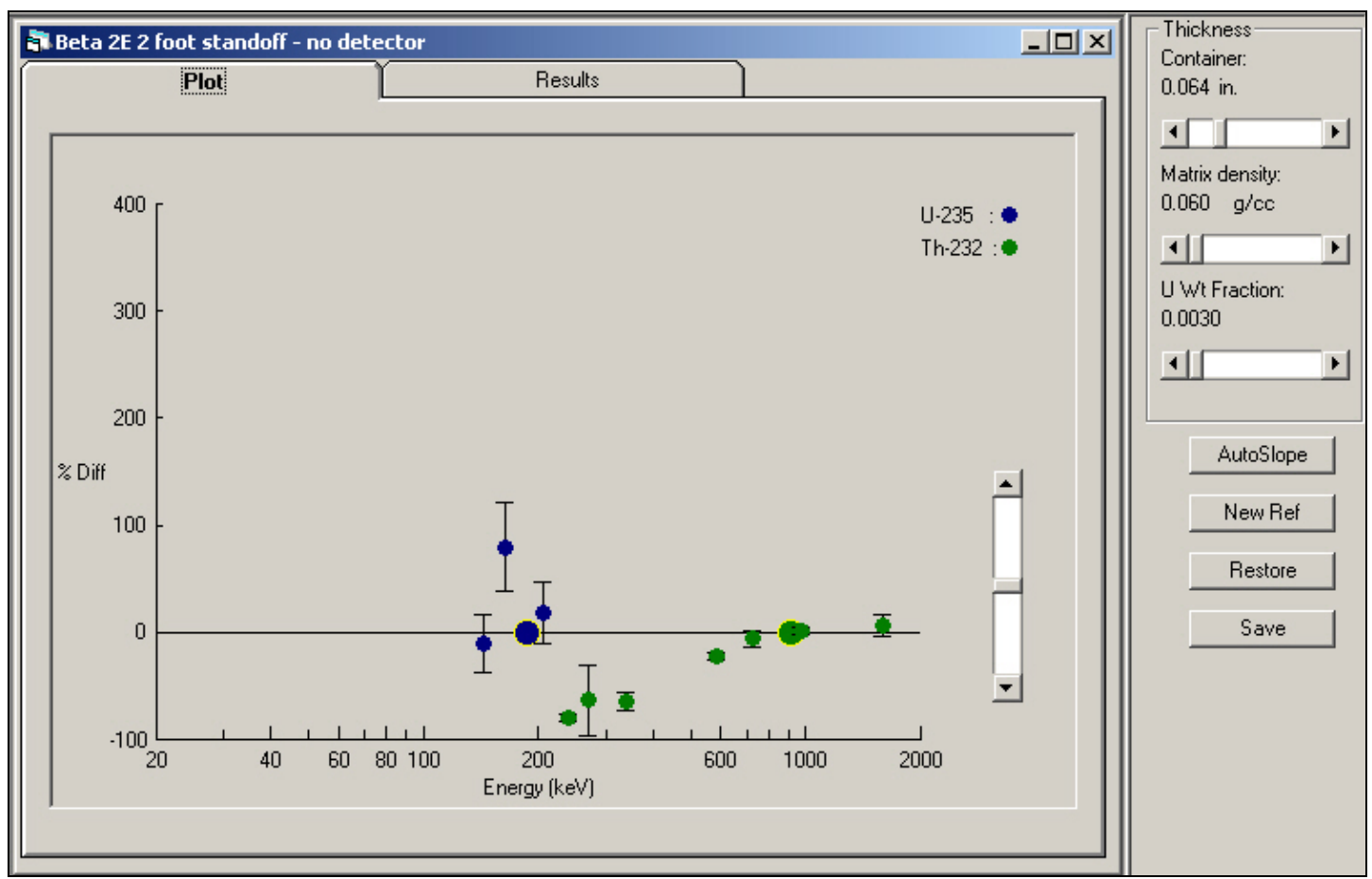

Figure 2a. ISOTOPIC software differential attenuation plot for the 55 gallon drum before adjustments. The $0.7 \mathrm{~g}$ of U-235 appears to have unbiased attenuation. The Th-232 appears to be under corrected. This difference suggests that the Th-232 is concentrated in a lump separate from the uranium.

\footnotetext{
${ }^{4}$ Another chemical form such as oxide would not be extremely different. The mass fraction would be at least 0.8 and the attenuation coefficient for the thorium tends to dominate because of the high $\mathrm{Z}$.
} 


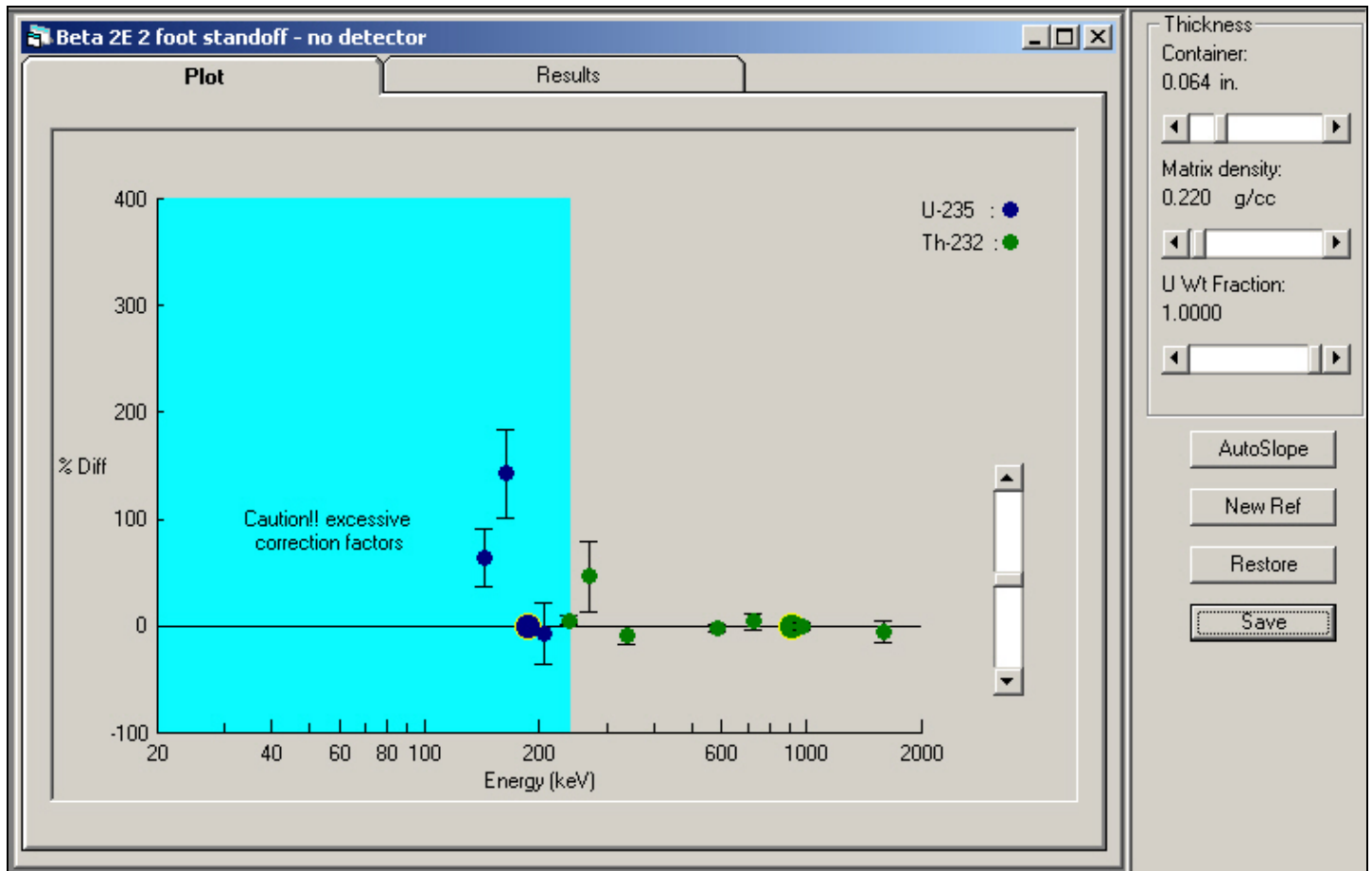

Figure 2b. ISOTOPIC software differential attenuation plot for the 55 gallon drum after adjustments. The uranium fraction was increased to 1.0 as a surrogate for thorium metal. The density of the matrix was also increased to $0.22 \mathrm{~g} / \mathrm{cc}$. Note the density cannot be taken literally in this situation because it is multiplied by the diameter of the drum for density thickness. The U-235 is clearly over-corrected.

In the second case, a hospital can purportedly containing combustible waste was found to have a count rate in the $2614 \mathrm{keV}$ peak which was 17 times background. Unlike the drum, the count rate in the $911 \mathrm{keV}$ peak from the hospital can was only $0.1 \mathrm{cps}$; much lower than the count rate of $2.6 \mathrm{cps}$ in the $2614 \mathrm{keV}$ peak. Therefore, U-232 is suspected.

This time, the gamma rays from Tl-208 were used to estimate the attenuation of the uranium gamma rays. When $\mathrm{U}-232$ is involved, it is expected to be comingled with the other uranium isotopes. From Figure 3a, both the gamma rays from Tl-208 and the gamma rays from U-235 appear under-corrected. The only way, by trial and error, of providing enough attenuation correction was to increase the uranium fraction to one. The matrix density was also increased until the error bar from the $583 \mathrm{keV}$ gamma ray touched the zero line. The $510 \mathrm{keV}$ gamma ray is unreliable because of interference from $511 \mathrm{keV}$ gamma rays from annihilation. The small error bars on the $583 \mathrm{keV}$ gamma ray were reason to overrule the apparent overcorrection of the $277 \mathrm{keV}$ and $860 \mathrm{keV}$ gamma rays.

These corrections increased the U-235 value from the initial analysis of $18 \mathrm{~g} \mathrm{U}-235$ to $1,190 \mathrm{~g} \mathrm{U}-235$. It was determined from records that the hospital can actually contained $2.1 \mathrm{~kg}$ of small HEU metal pieces on the bottom of the can. The $1.2 \mathrm{~kg}$ NDA result does not correct for the unfavorable geometry from the pieces being on the bottom of the can. The geometry factor was based on the assumption that the uranium was distributed throughout the can. A transmission source would also not have improved this measurement because of the fact that the items were on the bottom of the can. 
Y/EN-8270

May 26, 2009

Furthermore, a radiograph from the side would probably not have detected the uranium either. It this respect, differential attenuation is superior to a transmission source.

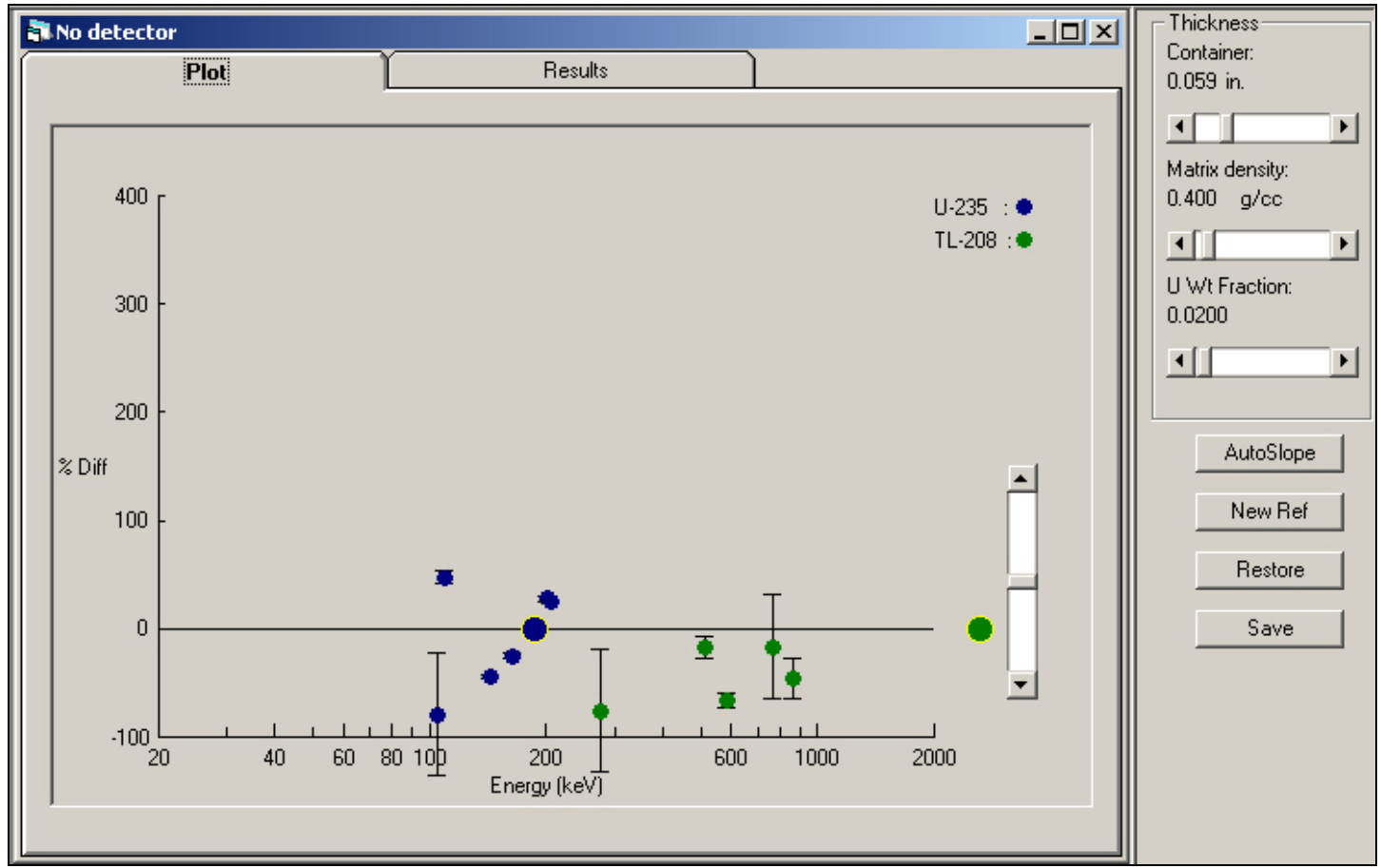

Figure 3a. ISOTOPIC software differential attenuation plot for the hospital can before adjustments. Both U-235 and Tl-208 gamma rays are under corrected.

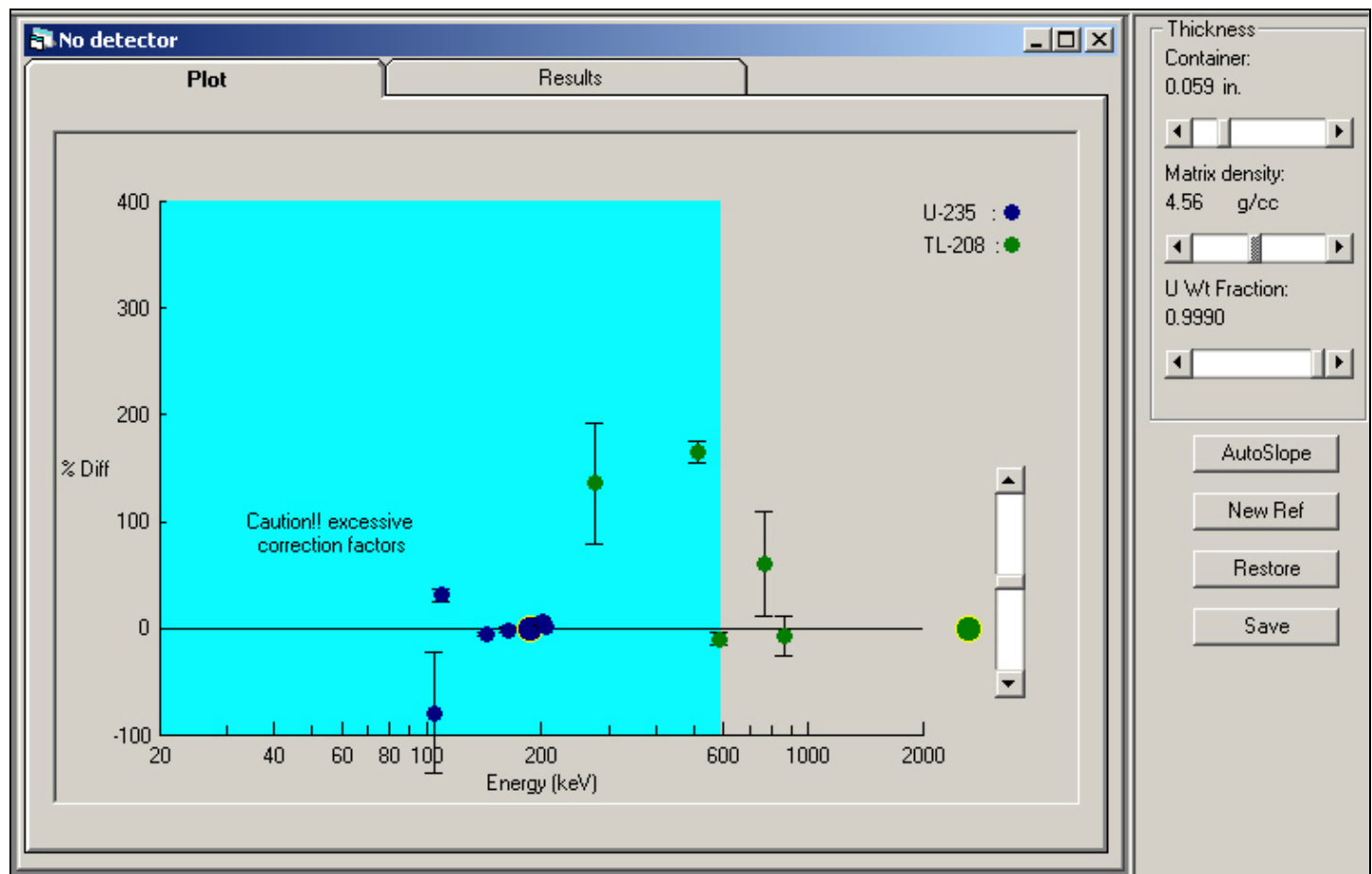

Figure 3b. ISOTOPIC software differential attenuation plot for the hospital can after adjustments. The uranium fraction was increased to 1.0 because uranium metal was suspected. The density of the matrix was also increased. Note the density cannot be taken literally in this situation because it is multiplied by the thickness of the drum for density thickness. 
$\mathrm{Y} / \mathrm{EN}-8270$

May 26, 2009

\section{Conclusion}

Two examples were presented where the count rates in the $2614 \mathrm{keV}$ gamma-ray peak indicated an anomaly in waste material. In these cases, further investigation was warranted. In the case of the hospital can, $2.1 \mathrm{~kg}$ of HEU appeared initially to be only a few grams in the initial analysis. Without differential attenuation analysis, those few grams could have been mistaken for waste. The use of the $2614 \mathrm{keV}$ gamma ray quickly caught the discrepancy. In the case of the drum, the $2614 \mathrm{keV}$ was caused by a relatively benign, from a safeguards perspective, piece of thorium metal. However, it did not belong in a drum labeled combustible waste and was removed. 